\title{
Intestinal ischemia after cardiac surgery: analysis of a large registry
}

Johan Nilsson ${ }^{1}$, Erika Hansson ${ }^{2}$ and Bodil Andersson ${ }^{2 *}$

\begin{abstract}
Background: Intestinal ischemia after cardiac surgery is a rare but severe complication with a high mortality. Early surgery can be lifesaving. The aim was to analyze the incidence, outcome, and risk factors for these patients.

Methods: A prospectively collected database with patients who underwent 18,879 cardiac surgical procedures between 1996 and 2011 was investigated. All patients with registered gastrointestinal complications were retrospectively reviewed. Univariate and multivariate analyses were performed to compare patients with and without intestinal ischemia.

Results: Seventeen patients suffered from intestinal ischemia (0.09\%), 10 of whom (59\%) died. By investigating preoperative parameters independent risk factors were steroids, peripheral vascular disease, cardiogenic shock, and New York Heart Association class 4. When including pre-, per-, and postoperative parameters, only postoperative ones were significant, including elevated creatinine (> $200 \mu \mathrm{mol} / \mathrm{L})$, prolonged ventilator time, need for intra-aortic balloon pump, and cerebrovascular insult (CVI). The gastrointestinal complications score (GICS) showed a ROC area of 0.87. This was superior compared with EuroSCORE (0.74), to predict intestinal ischemia.
\end{abstract}

Conclusions: Intestinal ischemia after cardiac surgery is more common in patients with a poor cardiac state, but the use of steroids, peripheral vascular disease, postoperative kidney failure, and CVI were also predictive. GICS score, developed for all Gl complications after cardiac surgery, is also of value in predicting this particular complication. The risk factors presented can be used as an aid in the diagnosis of these patients.

Keywords: Cardiac surgery, Gastrointestinal complications, Intestinal ischemia, Outcome, Risk factors

\section{Background}

Gastrointestinal (GI) emergencies are infrequent but severe complications after cardiac surgery procedures, with an incidence of $0.4-2.9 \%[1,2]$. The group is heterogeneous, including diagnoses such as upper and lower GI bleeding, acute pancreatitis, acute cholecystitis, perforation of the GI tract, paralytic ileus, and visceral ischemia. Intestinal ischemia is one of the most severe complications, with a mortality rate of $46-100 \%[3,4]$.

It can be a challenge to reach an early diagnosis. Patients with GI complications frequently present with atypical symptoms, often have several underlying diseases, and drug therapies, and may be unable to describe symptoms or react to examination due to sedation and analgesia. With intestinal ischemia, a delayed diagnosis

\footnotetext{
* Correspondence: bodil.andersson@med.lu.se

${ }^{2}$ Department of Surgery, Clinical Sciences, Lund University and Skane University Hospital, Lund, Sweden

Full list of author information is available at the end of the article
}

and surgical intervention can be fatal [5]. Various demographic and surgical variables and postoperative events have been suggested as risk factors for GI complications [1,6-9], and also for intestinal ischemia in particular [5,10-12]. This identification is important and can lead to earlier diagnosis and treatment.

Intestinal ischemia after cardiac surgery most often is due to a non-occlusive mesenteric ischemia (NOMI) $[13,14]$. This condition was first described in 1958, and even though the exact pathophysiological mechanism is not understood, it is related to a reduction in the splanchnic blood flow, which can be due to low cardiac output, and it may also be aggravated by inotropic support such as vasopressors, and by pre-existing atherosclerosis [13]. The ischemia is more seldom a cause of arterial emboli or thrombosis and venous thromboembolism [4].

\section{Biomed Central}

(c) 2013 Nilsson et al.; licensee BioMed Central Ltd. This is an Open Access article distributed under the terms of the Creative Commons Attribution License (http://creativecommons.org/licenses/by/2.0), which permits unrestricted use, distribution, and reproduction in any medium, provided the original work is properly cited. 
The aim of this study was to investigate the incidence of intestinal ischemia after cardiac surgery over time, and to identify risk factors for the disease and patient outcome by using a large database with prospectively collected material. We compared patients with suspected ischemia who underwent a negative laparotomy and patients diagnosed with intestinal ischemia.

\section{Methods}

Between January 1996 and December 2011, data from adult patients who underwent a total of 19,677 cardiac surgery procedures at Skane University Hospital were registered prospectively. We excluded patients who had coronary artery bypass grafting (CABG) without extracorporeal circulation $(N=452)$, surgery due to dissection or aneurysm in the aorta descendens $(N=87)$, heart transplantation $(N=205)$, laser surgery $(N=32)$, or were $<18$ years old $(N=21)$. The remaining 18,590 patients, who had 18,879 operations, were included for further analysis. CABG $(N=12,658)$ was the most common procedure, followed by various heart valve procedures $(N=2,220), \mathrm{CABG}$ and heart valve procedures combined $(N=2,055)$ and miscellaneous procedures, e.g. post-infarction septal rupture, aortic dissection type $\mathrm{A}$, and ascending aortic aneurysm, $(N=1,946)$.

The cardiac surgery database contains a total of 248 variables including preoperative, peroperative, and postoperative parameters. Variables previously described in the literature and risk factors from the European system for cardiac operative risk evaluation (EuroSCORE) [15] were chosen for further analysis. EuroSCORE, Higgins and Parsonnet score, that are general risk stratification systems designed to determine overall in-house or 30-day mortality, was evaluated for their ability to predict intestinal ischemia. A score specific for GI complications (GICS score) was also evaluated [9].

The case records of all patients registered as having had a GI complication were retrospectively reviewed and classified according to Andersson et al. [1]. Patients without GI complications were included in the control group. Patients who underwent a negative laparotomy were included in a separate group.

Prolonged ventilator time was defined as the use of a ventilator for more than $24 \mathrm{~h}$ after cardiac surgery. The need for inotropic support was registered if the patient required one or several inotropic drugs, e.g. norepinephrine, dobutamine, and dopamine, for more than $48 \mathrm{~h}$. Postoperative renal failure was defined as a serum creatinine level of above $200 \mu \mathrm{mol} / \mathrm{L}$. Intestinal ischemia was defined as ischemia diagnosed at endoscopy, abdominal surgery, or autopsy.

\section{Statistical analysis}

Values are given as median and interquartile range for continuous variables. For categorical data, absolute numbers and percentages are given. Univariate analysis for continuous variables was done with the Wilcoxon test. Categorical variables were analyzed by Pearson's test, except when the expected frequencies were less than 5 , in which case the Fisher's exact test was used. The analysis was based on available data. A probability level of less than 0.05 was considered significant. Multivariate analysis was performed using stepwise logistic regression. The inclusion for the full model was $p<0.2$. The limit for stepwise backward elimination was $p<0.1$. The discriminatory power of the different scoring models was evaluated by calculation of the area under the receiver operating characteristic (ROC) curves, with 95\% confidence limits. To compare the areas under the resulting ROC curves, the non-parametric approach described by DeLong et al. [16] was used. Missing values were replaced using the probability imputation technique. This was done before the selected variables from the univariate analysis were included in the multiple variable analyses and before the risk score was calculated [17].

Statistical analyses were performed with the Hmisc, Survival and Design packages of $\mathrm{R}$ software version 2.15.1, 2012 (R Foundation for Statistical Computing, Vienna, Austria).

The Ethics Committee for Clinical Research at Lund University, Sweden approved the study. Written informed consent was not obtained from the patients for publication of this report or any accompanying images, since we report of a large population and not about an individual patient. No image of an individual patient is accompanied.

\section{Results}

\section{Characteristics of patients with intestinal ischemia}

Seventeen patients, including 5 men and 12 women, were diagnosed as having intestinal ischemia during the study period. Median age was $69(60-75)$ years and median body mass index (BMI) was $26(24-29) \mathrm{kg} / \mathrm{m}^{2}$. Ten of the patients (59\%) died due to the complication.

\section{Incidence of intestinal ischemia}

Since intestinal ischemia after cardiac surgery is a rare event, even when large databases are investigated, a limited number of cases are identified. The present study present the lowest described incidence of this complication $(0.09 \%)$ with a decreasing incidence during the study period from $0.61 \%(N=10)$ during the first 5 years to $0.06 \%(N=7)$ during the last 11 years. 


\section{Endoscopic and radiological examinations and abdominal surgery}

In all but one patient, a surgeon was consulted. Seven patients underwent endoscopy (sigmoidoscopy or colonoscopy), which was diagnostic in 6 cases. All of these patients later had an abdominal exploration. Those who did not have an endoscopy either went directly for exploration $(N=8)$ or the ischemia was diagnosed at autopsy $(N=2)$. Abdominal X-ray was the only radiological examination in 5 of the cases with ischemia. All showed signs of paralysis with dilation of the intestines. Computed tomography (CT) was performed in 5 cases. In 2 cases, this showed dilatation of the small bowel or the colon, and in 2 cases also mural enhancement of the caecum and the distal ileum or the small bowel. In one patient, there was sign of pancreatitis with peripancreatic inflammation. In 2 cases, ultrasound was combined with a CT-scan and in one of these an X-ray was also conducted. The cardiac surgery and abdominal surgery performed for this group are presented in Table 1.

\section{Univariate risk factors for intestinal ischemia}

General patient characteristics, and preoperative state, and postoperative course are compared between patients with and without intestinal ischemia, operated during the time period (Tables 2 and 3).

The well-known cardiac surgery risk scores EuroSCORE, Parsonnet and Higgins score, and also the fairly new GICS score [9], were compared between patient groups (Table 4). The discrimination, represented by the area under the receiver operating characteristic (ROC) curve, was 0.87 (95\% CI 0.77-0.98) for the GICS score (Figure 1). For EuroSCORE, the ROC area was 0.74 (95\% CI 0.61-0.86).

\section{Multivariate risk factors for intestinal ischemia}

Data from the univariate analysis with $p<0.200$ and postoperative factors that were unlikely to be secondary to GI complications (e.g. length of stay at the intensive care unit and multiple organ failure) were included in the multivariate model, as presented in Table 5. We also performed a sub analysis including only preoperative factors (Table 6).

\section{Comparison of patients with intestinal ischemia and patients with negative laparotomy}

Four patients, with a median age of 72 (65-77) years, were suspected of having intestinal ischemia but underwent laparotomies with normal findings during the same time period. In both groups, cardiac surgery reoperation was common (2/4 and 9/17) and each of postoperative sepsis, multiple organ failure, kidney failure, and atrial fibrillation was seen in $25-50 \%$ in both groups. The time to abdominal surgery was generally longer for the patients with negative laparotomy, 24 (24-39) h as opposed to 8 (8-43) h for patients with intestinal ischemia, but the difference did not reach statistical significance in this small material. Leucocyte count was significantly higher for patients with intestinal ischemia (14 (10-23) $10^{9} / \mathrm{L}$ as opposed to $8.2(7.5-9.1) 10^{9} / \mathrm{L}$ for patients with negative laparotomy; $p=0.018$ ), but no other laboratory parameters showed any significant difference, including lactate $(3.0(2.1-6.3) \mathrm{mmol} / \mathrm{L}$ and $3.0(2.1-6.3) \mathrm{mmol} / \mathrm{L}$, respectively; $p=0.91)$.

\section{Discussion}

In this single-center study, based on a large prospectively collected database, intestinal ischemia after cardiac surgery was investigated. We found a lower incidence,

Table 1 Cardiac surgical procedure and abdominal surgery on patients with intestinal ischemia

\begin{tabular}{ll}
\hline Abdominal operation (number of patients) & Cardiac surgical procedure (number of patients) \\
\hline Small bowel resection (1) & CABG (1) \\
Small bowel resection and embolectomy (1) & CABG + mitrale valve surgery (1) \\
lleocecal resection (1) & CABG + VSD (1) \\
Hemicolectomy (1) & CABG (1) \\
$\begin{array}{l}\text { Left sided colectomy and colostomy (1) } \\
\text { Colectomy, ileostomy (4) }\end{array}$ & Surgery to aorta ascendens, including one with aortic valve replacement (2), CABG (1), \\
$\begin{array}{l}\text { Hemicolecomy and colectomy with ileostomy, both with } \\
\text { cholecystectomy (2) }\end{array}$ & CABG (2) \\
$\begin{array}{l}\text { Explorative laparotomy - no resection due to massive } \\
\text { bowel ischemia (4) }\end{array}$ & CABG (2), Aortic valve surgery (1), Left ventricular assist device (1) \\
No surgery* (2) & CABG (2) \\
\hline
\end{tabular}

CABG coronary artery bypass grafting, VSD ventricular septal defect, *diagnosis at autopsy. 
Table 2 Preoperative univariate risk factors for intestinal ischemia after cardiac surgery

\begin{tabular}{|c|c|c|c|c|}
\hline Variable & $N$ & Control group $N=18862$ & Patients with intestinal ischemia $N=17$ & $p$ value \\
\hline Age (years)* & 18879 & $69(60-75)$ & $69(59-73)$ & 0.45 \\
\hline Female gender & 18879 & $5187(27)$ & $6(35)$ & 0.47 \\
\hline BMI $\left(\mathrm{kg} / \mathrm{m}^{2}\right)^{*}$ & 15066 & $26(24-29)$ & $25(22-27)$ & 0.15 \\
\hline Haemoglobin $(g / L)^{*}$ & 15859 & $135(123-145)$ & $130(118-140)$ & 0.56 \\
\hline Creatinine $>200(\mu \mathrm{mol} / \mathrm{L})$ & 18144 & $340(2)$ & $2(12)$ & 0.04 \\
\hline Dialysis & 18652 & $226(1)$ & 0 & 1 \\
\hline Hemodynamic instable & 18876 & $272(1)$ & $2(12)$ & $<0.001$ \\
\hline Smoking & 8518 & $849(10)$ & $2(25)$ & 0.19 \\
\hline Emergency cardiac surgery & 18879 & $1923(10)$ & $7(41)$ & $<0.001$ \\
\hline Chronic obstructive pulmonary disease & 18653 & $1756(9)$ & $2(12)$ & 0.67 \\
\hline Stroke & 18653 & $830(4)$ & $3(18)$ & 0.038 \\
\hline Peripheral vascular disease & 18653 & $2388(13)$ & $7(41)$ & $<0.001$ \\
\hline Left ventricular ejection fraction $<30 \%$ & 18879 & $1482(8)$ & $2(12)$ & 0.39 \\
\hline Instable angina & 18879 & $1542(8)$ & $5(29)$ & 0.01 \\
\hline Cardiogenic shock & 16091 & $282(2)$ & $3(23)$ & 0.001 \\
\hline Atrial fibrillation & 14786 & $1552(11)$ & $2(14)$ & 0.65 \\
\hline Anticoagulants & 18879 & $2640(14)$ & $5(29)$ & 0.078 \\
\hline Steroids & 18879 & $212(1)$ & $2(12)$ & 0.016 \\
\hline IABP & 18871 & $576(3)$ & $2(12)$ & 0.094 \\
\hline Diabetes mellitus & 18652 & $3462(19)$ & $3(18)$ & 1 \\
\hline NYHA 4 & 18879 & $2652(12)$ & $9(53)$ & $<0.001$ \\
\hline
\end{tabular}

$N$ is the number of non missing values, values in parentheses are percentages, except median (interquartile range)* $B M I$ body mass index, $I A B P$ intra-aortic balloon pump, NYHA New York Heart Association.

$0.09 \%$, than previously presented, but the mortality rate was comparable with others $[4,10,12,18-20]$. Risk factors were identified that can aid in the diagnosis. To reduce the delay in diagnosis and allow effective use of all therapeutic options, a high index of suspicion for intestinal ischemia after cardiac surgery is warranted, in order to reduce mortality.
Patients with intestinal ischemia after cardiac surgery often have vague and non-specific symptoms. They are often ventilated and sedated, making them unable to react to physical examination. The difficulty in making the diagnosis contributes to the dismal outcome, despite advances in critical care. Thus, in a patient with a septic condition early after surgery, this diagnosis must always

Table 3 Per- and postoperative univariate risk factors for intestinal ischemia after cardiac surgery

\begin{tabular}{|c|c|c|c|c|}
\hline Variable & $N$ & Control group $N=18862$ & Patients with intestinal ischemia $N=17$ & $p$ value \\
\hline CPB time (minutes)* & 18879 & $92(71-123)$ & $120(82-169)$ & 0.026 \\
\hline Creatinine $>200(\mu \mathrm{mol} / \mathrm{L})$ & 16285 & $598(4)$ & $10(59)$ & $<0.001$ \\
\hline Dialysis & 16361 & $193(1)$ & $3(18)$ & 0.001 \\
\hline Reoperation due to bleeding & 18875 & $942(5)$ & $3(18)$ & 0.05 \\
\hline Prolonged ventilator time ${ }^{* *}$ & 17153 & $1921(11)$ & $13(76)$ & $<0.001$ \\
\hline Arrhythmia & 14335 & $4929(34)$ & $8(62)$ & 0.074 \\
\hline Atrial fibrillation & 16568 & $4998(30)$ & $8(47)$ & 0.18 \\
\hline IABP & 16284 & $282(2)$ & $4(24)$ & $<0.001$ \\
\hline Intropine $>24 \mathrm{~h}$ & 16284 & $1039(6)$ & $10(59)$ & $<0.001$ \\
\hline Cardiac infarction & 16284 & $405(2)$ & $4(24)$ & $<0.001$ \\
\hline Cerebrovascular insult & 16284 & $173(1)$ & $4(24)$ & $<0.001$ \\
\hline
\end{tabular}

$N$ is the number of non missing values, values in parentheses are percentages, except median (interquartile range) ${ }^{*}, C P B$ cardiopulmonary bypass time, $I A B P$ intraaortic balloon pump, ${ }^{* *} 24$ hours after cardiac surgery. 
Table 4 Cardiac surgery scoring systems as predictors for intestinal ischemia

\begin{tabular}{lccc}
\hline $\begin{array}{l}\text { Scoring } \\
\text { system }\end{array}$ & $\begin{array}{c}\text { Control group } \\
(\boldsymbol{N}=\mathbf{1 8 8 6 2})\end{array}$ & $\begin{array}{c}\text { Patients with intestinal } \\
\text { ischemia }(\boldsymbol{N}=\mathbf{1 7})\end{array}$ & $\boldsymbol{p}$ value \\
\hline $\begin{array}{l}\text { Euro } \\
\text { SCORE }\end{array}$ & $5.0(3.0-8.0)$ & $8.0(7.0-12)$ & $<0.001$ \\
$\begin{array}{l}\text { Higgins } \\
\text { score }\end{array}$ & $2.0(1.0-5.0)$ & $7.0(4.0-10)$ & $<0.001$ \\
$\begin{array}{l}\text { Parsonnet } \\
\text { score }\end{array}$ & $9.0(3.0-16)$ & $10(5.0-17)$ & 0.81 \\
GICS score & $2.0(0.0-4.5)$ & $9.0(6.0-11)$ & $<0.001$ \\
\hline
\end{tabular}

be considered. In the present study, when investigating preoperative factors we found the use of steroids, peripheral vascular disease, cardiogenic chock, and NYHA class 4 to be independent prognostic factors for development of the complication. Peripheral vascular disease has previously been pointed out as a risk factor as well as a poor preoperative cardiac condition $[5,10,12]$. In one older publication, the use of steroids - but in that case postoperatively - was a factor associated with an increased risk of general surgical complications after cardiac surgery [21]. In our study, advanced age, previously suggested to be associated with a higher risk $[4,10,18]$ was not found to be a risk factor.

When investigating relevant factors from the entire hospital stay, we found only postoperative factors, including elevated creatinine, the need for IABP, prolonged ventilator time, and CVI, to be independent risk factors. The need for IABP (a commonly used form of circulatory support for patients with postoperative low cardiac output syndrome) has previously been noted $[5,12]$, as has prolonged ventilation and dialysis support [10]. Stroke has been found to be more common in patients with gastrointestinal complications in cardiac surgery, but previously not described as an independent risk factor [22].

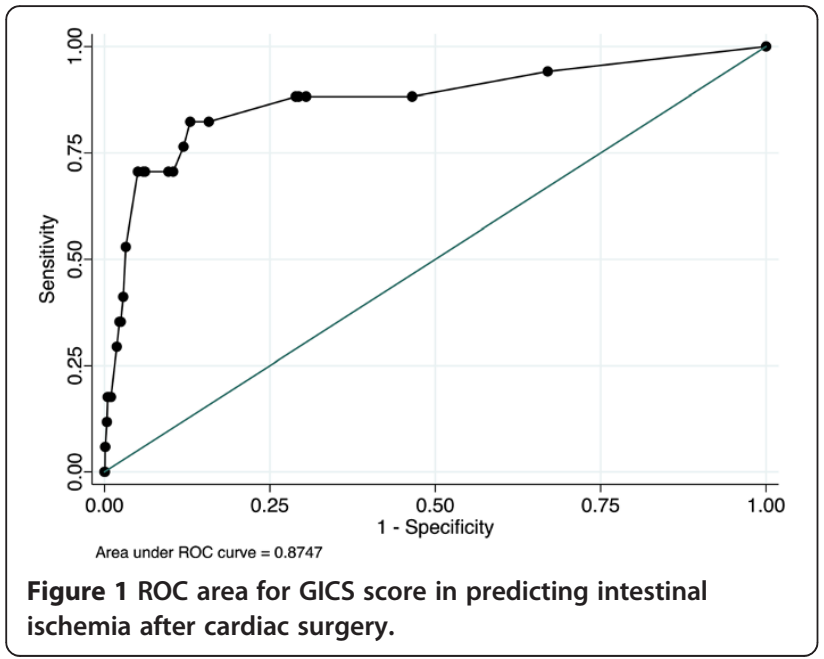

Table 5 Multivariate risk factors for intestinal ischemia after cardiac surgery

\begin{tabular}{lcc}
\hline Variable & $\begin{array}{c}\text { Odds Ratio (95\% } \\
\text { confidence interval) }\end{array}$ & $\boldsymbol{p}$ value \\
\hline $\begin{array}{l}\text { Postoperative creatinine }>200 \\
\text { ( } \mathrm{mmol} / \mathrm{L})\end{array}$ & $17.5(5.8-53)$ & $<0.001$ \\
IABP & $3.5(1.0-12)$ & 0.046 \\
Prolonged ventilator time* & $6.2(1.7-23)$ & 0.006 \\
Cerebrovascular insult & $7.8(2.3-27)$ & 0.001 \\
\hline
\end{tabular}

IABP intra-aortic balloon pump, *24 hours after cardiac surgery.

The GICS score [9], which was developed as a scoring model for all GI complications after cardiac surgery, was also predictive for intestinal ischemia alone, with a ROC area of 0.87 . This model includes the factors age $>80$ years, active smoker, preoperative inotropic support, NYHA class 3 and 4, cardiopulmonary bypass time of $>$ $150 \mathrm{~min}$, and the postoperative factors atrial fibrillation, heart failure, vascular complication, and reoperation due to bleeding.

The most common pathophysiological explanation for intestinal ischemia in these patients is the systemic hypo perfusion state and splanchnic vasoconstriction that lead to NOMI $[13,14]$. In some studies, survivors of this complication have had surgical intervention earlier $[5,11]$. However, early laparotomies do not necessarily mean survival in cases of extensive ischemia [23]. An alternative to laparotomy would be diagnostic laparoscopy [24]. Angiographically proven NOMI can also be treated with selective intra-arterial bolus injection and subsequent intra-arterial infusion of e.g. tolazoline, papaverine, or prostaglandin E2 $[12,20,25]$. In a recently published prospective study of 865 patients arterial angiography was performed if NOMI was suspected, with diagnosis of 78 cases of NOMI and 10 with unremarkable findings [26]. This is, however, a much higher incidence than is seen for clinically relevant mesenteric ischemia.

Four patients in this patient material were subjected to negative laparotomies, and we analyzed differences, including in laboratory findings. No major differences were found between the groups, except that leucocyte count was higher for patients with intestinal ischemia, and the time to abdominal surgery tended to be longer

Table 6 Preoperative multivariate risk factors for intestinal ischemia after cardiac surgery

\begin{tabular}{lcc}
\hline Variable & $\begin{array}{c}\text { Odds Ratio (95\% } \\
\text { confidence interval) }\end{array}$ & $\boldsymbol{p}$ value \\
\hline Steroids & $9.4(2.1-43)$ & 0.004 \\
$\begin{array}{l}\text { Peripheral vascular } \\
\text { disease }\end{array}$ & $3.7(1.4-9.9)$ & 0.008 \\
Cardiogenic chock & $4.9(1.2-19)$ & 0.023 \\
NYHA 4 & $4.2(1.6-13)$ & 0.004 \\
\hline
\end{tabular}

NYHA New York Heart Association. 
for the patients with a negative laparotomy. Edwards et al. [27] concluded that no clinical, biochemical, or hematological marker has been shown to be discriminatory for ischemia, and plain radiography does not reliably diagnose mesenteric ischemia. Pathological laboratory findings such as elevated lactate are late presentations, as well as findings on CT such as mural enhancement and gas in the bowel wall. Larger studies are currently lacking to reliably advocate the routine clinical use of novel markers such as mucosal damage markers, e.g. intestinal fatty acid-binding protein [28].

It has been suggested that patients should undergo routine endoscopic examination of the colon early after bypass and when clinically indicated [29]. In the present study, almost half of the patients underwent coloscopy, most of them with diagnostic findings. However, both radiological and endoscopic investigations are time consuming. Patients with a high index of suspicion of the diagnosis should therefore be taken directly to intervention.

The incidence of intestinal ischemia after cardiac surgery varies in the literature. The findings of the present study are in line with the observation of Allen et al. [18]. It is worth noting that a decrease in the incidence was seen during our study period. There was no obvious specific change in postoperative care, but regarding preoperative status, fewer patients with one of the identified preoperative risk factors - cardiogenic shock - had been subjected to emergency cardiac surgery during the last years. Instead, these patients were preferentially managed with percutaneous coronary intervention. We believe that this could explain the lower incidence to some extent.

Some limitations that must be mentioned are those inherent in research based on large databases, including missing values and also a lack of warranted parameters, e.g. laboratory data. Since the diagnosis is infrequent, the numbers of patients with the complication are limited, which could mean that there is a risk of failing to identify parameters of importance.

\section{Conclusions}

We found intestinal ischemia after cardiac surgery to be an uncommon complication, but associated with a high mortality. In our struggle to find characteristics of patients at risk, we identified several risk factors, reflecting patients with a poor preoperative state and postoperative complications, including kidney failure, CVI, prolonged ventilator time, and the use of IABP. In future, we must continue our efforts to diagnose these patients earlier, to reduce mortality. The GICS score has proved to be a useful tool in this important task.

\section{Abbreviations}

BMl: Body mass index; CABG: Coronary artery bypass grafting; CT: Computed tomography; CVI: Cerebrovascular insult; Gl: Gastrointestinal; GICS: Gastrointestinal complications score; IABP: Intra-aortic balloon pump; NOMI: Non-occlusive mesenteric ischemia; NYHA: New York Heart Association; ROC: The receiver operating characteristic.

\section{Competing interests}

The authors declare that they have no competing interests.

\section{Authors' contributions}

JN participated in the design of the study and in data collection, and performed the statistical analysis. EH participated in data collection and drafted the manuscript. BA designed the study, participated in data collection, and wrote the manuscript. All authors read and approved the final manuscript.

\section{Acknowledgements}

This study was made possible by grants from the Swedish Heart-Lung Foundation, the Swedish Society of Medicine, government grants for clinical research, and the Sparres Foundation.

\section{Author details}

'Department of Cardiothoracic Surgery, Clinical Sciences, Lund University and Skane University Hospital, Lund, Sweden. 'Department of Surgery, Clinical Sciences, Lund University and Skane University Hospital, Lund, Sweden.

Received: 15 April 2013 Accepted: 6 June 2013

Published: 18 June 2013

\section{References}

1. Andersson B, Nilsson J, Brandt J, Hoglund P, Andersson R: Gastrointestinal complications after cardiac surgery. Br J Surg 2005, 92:326-333.

2. Christenson JT, Schmuziger M, Maurice J, Simonet F, Velebit V: Postoperative visceral hypotension the common cause for gastrointestinal complications after cardiac surgery. Thorac Cardiovasc Surg 1994, 42:152-157

3. Abboud B, Daher R, Sleilaty G, Madi-Jebara S, El Asmar B, Achouch R, Jebara $\mathrm{V}$ : Is prompt exploratory laparotomy the best attitude for mesenteric ischemia after cardiac surgery? Interact Cardiovasc Thorac Surg 2008, 7:1079-1083.

4. Albes JM, Schistek R, Baier R, Unger F: Intestinal ischemia associated with cardio-pulmonary-bypass surgery: a life threatening complication. $J$ Cardiovasc Surg (Torino) 1991, 32:527-533.

5. Ghosh S, Roberts N, Firmin RK, Jameson J, Spyt TJ: Risk factors for intestinal ischaemia in cardiac surgical patients. Eur J Cardiothorac Surg 2002, 21:411-416.

6. Byhahn C, Strouhal U, Martens S, Mierdl S, Kessler P, Westphal K: Incidence of gastrointestinal complications in cardiopulmonary bypass patients. World J Surg 2001, 25:1140-1144.

7. Mangi AA, Christison-Lagay ER, Torchiana DF, Warshaw AL, Berger DL: Gastrointestinal complications in patients undergoing heart operation: an analysis of 8709 consecutive cardiac surgical patients. Ann Surg 2005, 241:895-901. discussion 901-4.

8. Filsoufi F, Rahmanian PB, Castillo JG, Scurlock C, Legnani PE, Adams DH: Predictors and outcome of gastrointestinal complications in patients undergoing cardiac surgery. Ann Surg 2007, 246:323-329.

9. Andersson B, Andersson R, Brandt J, Hoglund P, Algotsson L, Nilsson J: Gastrointestinal complications after cardiac surgery - improved risk stratification using a new scoring model. Interact Cardiovasc Thorac Surg 2010, 10:366-370.

10. Chaudhuri N, James J, Sheikh A, Grayson AD, Fabri BM: Intestinal ischaemia following cardiac surgery: a multivariate risk model. Eur J Cardiothorac Surg 2006, 29:971-977.

11. Pang PY, Sin YK, Lim CH, Su JW, Chua YL: Outcome and survival analysis of intestinal ischaemia following cardiac surgery. Interact CardiovasC Thorac Surg 2012, 15:215-218.

12. Huwer H, Winning J, Straub U, Isringhaus H, Kalweit G: Clinically diagnosed nonocclusive mesenteric ischemia after cardiopulmonary bypass: retrospective study. Vascular 2004, 12:114-120. 
13. Ende N: Infarction of the bowel in cardiac failure. N Engl J Med 1958, 258:879-881.

14. Kazui T, Yamasaki M, Abe K, Watanabe S, Kawazoe K: Non-obstructive mesenteric ischemia: a potentially lethal complication after cardiovascular surgery: report of two cases. Ann Thorac Cardiovasc Surg 2012, 18:56-60.

15. Nashef SA, Roques F, Michel P, Gauducheau E, Lemeshow S, Salamon R: European system for cardiac operative risk evaluation (EuroSCORE). Eur J Cardiothorac Surg 1999, 16:9-13.

16. DeLong ER, DeLong DM, Clarke-Pearson DL: Comparing the areas under two or more correlated receiver operating characteristic curves: a nonparametric approach. Biometrics 1988, 44:837-845.

17. Schemper M, Smith TL: Efficient evaluation of treatment effects in the presence of missing covariate values. Stat Med 1990, 9:777-784.

18. Allen KB, Salam AA, Lumsden AB: Acute mesenteric ischemia after cardiopulmonary bypass. J Vasc Surg 1992, 16:391-395. discussion 395-6.

19. Garofalo M, Borioni R, Nardi P, Turani F, Bertoldo F, Forlani S, Pellegrino A, Chiariello L: Early diagnosis of acute mesenteric ischemia after cardiopulmonary bypass. J Cardiovasc Surg (Torino) 2002, 43:455-459.

20. Klotz S, Vestring T, Rotker J, Schmidt C, Scheld HH, Schmid C: Diagnosis and treatment of nonocclusive mesenteric ischemia after open heart surgery. Ann Thorac Surg 2001, 72:1583-1586.

21. Spotnitz WD, Sanders RP, Hanks JB, Nolan SP, Tribble CG, Bergin JD, Zacour RK, Abbott RD, Kron IL: General surgical complications can be predicted after cardiopulmonary bypass. Ann Surg 1995, 221:489-496. discussion 496-7.

22. D'Ancona G, Baillot R, Poirier B, Dagenais F, de Ibarra Jl, Bauset R, Mathieu P, Doyle D: Determinants of gastrointestinal complications in cardiac surgery. Tex Heart Inst J 2003, 30:280-285.

23. Hasan S, Ratnatunga C, Lewis CT, Pillai R: Gut ischaemia following cardiac surgery. Interact Cardiovasc Thorac Surg 2004, 3:475-478.

24. Hackert T, Kienle P, Weitz J, Werner J, Szabo G, Hagl S, Buchler MW, Schmidt $\mathrm{J}$ : Accuracy of diagnostic laparoscopy for early diagnosis of abdominal complications after cardiac surgery. Surg Endosc 2003, 17:1671-1674.

25. Niederhauser U, Genoni M, von Segesser LK, Bruhlmann W, Turina MI: Mesenteric ischemia after a cardiac operation: conservative treatment with local vasodilation. Ann Thorac Surg 1996, 61:1817-1819.

26. Groesdonk HV, Klingele M, Schlempp S, Bomberg H, Schmied W, Minko P, Schafers $\mathrm{HJ}$ : Risk factors for nonocclusive mesenteric ischemia after elective cardiac surgery. J Thorac Cardiovasc Surg 2013, 145:1603-1610.

27. Edwards M, Sidebotham D, Smith M, Leemput JV, Anderson B: Diagnosis and outcome from suspected mesenteric ischaemia following cardiac surgery. Anaesth Intensive Care 2005, 33:210-217.

28. Demir IE, Ceyhan GO, Friess H: Beyond lactate: is there a role for serum lactate measurement in diagnosing acute mesenteric ischemia? Dig Surg 2012, 29:226-235.

29. Fitzgerald T, Kim D, Karakozis S, Alam H, Provido H, Kirkpatrick J: Visceral ischemia after cardiopulmonary bypass. Am Surg 2000, 66:623-626.

doi:10.1186/1749-8090-8-156

Cite this article as: Nilsson et al: Intestinal ischemia after cardiac

surgery: analysis of a large registry. Journal of Cardiothoracic Surgery 2013 8:156.

\section{Submit your next manuscript to BioMed Central and take full advantage of:}

- Convenient online submission

- Thorough peer review

- No space constraints or color figure charges

- Immediate publication on acceptance

- Inclusion in PubMed, CAS, Scopus and Google Scholar

- Research which is freely available for redistribution 